\title{
The Growth of Pseudomonas putida on Chlorinated Aliphatic Acids and its Dehalogenase Activity
}

\author{
By J. HOWARD SLATER,* DAVID LOVATT,* \\ ANDREW J. WEIGHTMAN,* ERIC SENIOR $†$ AND ALAN T. BULL $\dagger$ \\ * Department of Environmental Sciences, University of Warwick, \\ Coventry CV4 $7 A L$ \\ $\dagger$ Department of Applied Biology, University of Wales Institute of Science \\ and Technology, King Edward VII Avenue, Cardiff CF1 $3 N U$
}

(Received 12 January 1979)

Two strains of Pseudomonas putida, S3 and P3, were shown to contain dehalogenase activity against monochloroacetate, dichloroacetate, 2-monochloropropionate and 2,2'-dichloropropionate but differed markedly in their levels of enzyme activity. Strain S3 had activities of less than $1 \mu \mathrm{mol}$ substrate converted (mg protein) $)^{-1} \mathrm{~h}^{-1}$ and was unable to grow on any of nine chlorinated compounds tested. Strain P3 had enzyme activities 10 to 40 times greater than those of strain S3 but was capable of growth only on 2-monochloropropionate and $2,2^{\prime}$-dichloropropionate. In strain P3, dehalogenase activity was induced by a number of chlorinated compounds other than those that acted as growth substrates. Strain P3 dehalogenase activity dehalogenated C-2 substituted compounds. The evidence of the dehalogenase activity profiles in chemostat cultures and from thermal denaturation experiments suggested that there was more than one dehalogenase enzyme in $P$. putida strain P3. In crude extract, the enzyme activity was optimal at $\mathrm{pH} 7.9$ to 8.1 and apparent $K_{\mathrm{m}}$ values were in the millimolar range for the four major substrates, monochloroacetate, dichloroacetate, 2-monochloropropionate and 2,2'-dichloropropionate.

\section{INTRODUCTION}

Halogenated compounds occur widely in the biosphere either as natural products (Fowden, 1968; Suida \& DeBernardis, 1973) or, increasingly, as xenobiotic compounds derived from the use of herbicides and pesticides (Kearney \& Kaufman, 1969; Leasure, 1964; Audus, 1976). A few micro-organisms have been isolated that are capable of utilizing halogenated aliphatic acids as sole carbon and energy sources for growth. For example, Jensen $(1957 a, b, 1959,1960)$ isolated various bacteria and fungi that were capable of growing on monochloroacetic acid, dichloroacetic acid, trichloroacetic acid, 2-monochloropropionic acid and 2,2'-dichloropropionic acid. The active ingredient in the herbicide Dalapon, a widely and successfully used chlorinated aliphatic acid herbicide (Foy, 1969), is 2,2'dichloropropionic acid, and this has been shown to be readily degraded by soil microorganisms, particularly bacteria (Magee \& Colmer, 1959; Hirsch \& Alexander, 1960; Macgregor, 1963; Burge, 1969; Berry et al., 1976).

Growth on these compounds depends on the induction of an enzyme known either as dehalogenase (Jensen, 1960, 1963) or as halidohydrolase (Goldman et al., 1968; Goldman, 1972). Dehalogenases catalyse the hydrolytic removal of halogens, usually from C-2 substitutions, yielding either hydroxy- or oxo-carboxylic acids from the mono- or di-substituted acids, respectively (Davies \& Evans, 1962; Kearney et al., 1964; Goldman, 1965; Goldman et al., 1968; Little \& Williams, 1969, 1971). 
In this paper we describe a study of two related strains of $P_{\text {seudomonas }}$ putida, strains S3 and P3 (Senior et al., 1976), differing in their capacity to utilize a range of chlorinated acetic, propionic and butyric acids, and report the basic characterization of their dehalogenase activities. Some of the results reported here have been the subject of a preliminary communication (Slater et al., 1976).

\section{METHODS}

Abbreviations. MCA, Monochloroacetic acid; DCA, dichloroacetic acid; TCA, trichloroacetic acid; 2MCPA, 2-monochloropropionic acid; 3MCPA, 3-monochloropropionic acid; 22DCPA, 2,2'-dichloropropionic acid; 23DCPA, 2,3-dichloropropionic acid; 2MCBA, 2-monochlorobutyric acid; 3MCBA, 3-monochlorobutyric acid; 4MCBA, 4-monochlorobutyric acid.

Bacterial strains, maintenance and growth. The two strains of Pseudomonas putida, S3 and P3, were isolated from a microbial community obtained by continuous-flow enrichment culture with 22DCPA as the sole carbon and energy source (Senior et al., 1976).

The growth medium contained $\left(\mathrm{g} \mathrm{l}^{-1}\right): \mathrm{K}_{2} \mathrm{HPO}_{4}, 1 \cdot 5 ; \mathrm{KH}_{2} \mathrm{PO}_{4}, 0.5 ;\left(\mathrm{NH}_{4}\right)_{2} \mathrm{SO}_{4}, 0.5 ; \mathrm{MgSO}_{4} .7 \mathrm{H}_{2} \mathrm{O}, 0 \cdot 2$; and $10.0 \mathrm{ml}$ of a trace element solution containing $\left(\mathrm{gl}^{-1}\right): \mathrm{Na}_{2}$ EDTA. $2 \mathrm{H}_{2} \mathrm{O}, 12 \cdot 0 ; \mathrm{FeSO}_{4} .7 \mathrm{H}_{2} \mathrm{O}, 2 \cdot 0 ; \mathrm{CaCl}_{2}$, $1.0 ; \mathrm{Na}_{2} \mathrm{SO}_{4}, 10 \cdot 0 ; \mathrm{ZnSO}_{4} .7 \mathrm{H}_{2} \mathrm{O}, 0 \cdot 4 ; \mathrm{MnSO}_{4} .4 \mathrm{H}_{2} \mathrm{O}, 0 \cdot 4 ; \mathrm{CuSO}_{4} .5 \mathrm{H}_{2} \mathrm{O}, 0 \cdot 1 ; \mathrm{Na}_{2} \mathrm{MoO}_{4} .2 \mathrm{H}_{2} \mathrm{O}, 0 \cdot 1$; and $0.5 \mathrm{ml}$ concentrated $\mathrm{H}_{2} \mathrm{SO}_{4}$. The $\mathrm{pH}$ of the mineral medium was adjusted to 7.0 before autoclaving. Carbon sources were supplied as different volumes of stock solutions $(10 \%, \mathrm{w} / \mathrm{v} ; \mathrm{pH} 7 \cdot 0)$ to give final concentrations of $0.5 \mathrm{~g} \mathrm{C} \mathrm{l}^{-1}$. Solutions of chlorinated compounds were filter-sterilized to prevent thermal dechlorination. Pseudomonas putida strain $\mathrm{S} 3$ was maintained on mineral salts medium supplemented with sodium succinate and P.putida strain P3 with either 2MCPA or 22DCPA as the sole carbon and energy source. Closed cultures, usually $100 \mathrm{ml}$ culture in $250 \mathrm{ml}$ conical flasks, were incubated at $30^{\circ} \mathrm{C}$ and growth was estimated by measuring the culture absorbance $\left(A_{600}\right)$ in either a Corning model 252 colorimeter (red filter) or a Unicam SP1700 spectrophotometer.

Chemostat cultures were grown in LHE Series 500 Fermenter Units (LH Engineering, Stoke Poges, Bucks.) having a culture working volume of $0.8 \mathrm{l}$. Cultures were agitated at $1000 \mathrm{rev}$. $\mathrm{min}^{-1}$ and supplied with air at the rate of $0.81 \mathrm{~min}^{-1}$. Fresh medium was fed to the growth vessel by a flow inducer (Watson Marlow, Falmouth, Cornwall). The growth temperature was controlled at $30^{\circ} \mathrm{C}$. The growth medium was that used for the closed cultures and gave carbon-limited growth. In some experiments two carbon sources (sodium succinate with a chlorinated aliphatic acid) were supplied, both at $0.5 \mathrm{~g} \mathrm{C} \mathrm{l}^{-1}$.

Estimation of chloride ions. Chloride ions were determined in a Marius Chlor-0-Counter (F. T. Scientific, U.K.). Samples $(0.1$ or $1.0 \mathrm{ml})$ were added to $25 \mathrm{ml}$ of a base counting solution (100 ml glacial acetic acid and $8.0 \mathrm{ml}$ concentrated nitric acid in 1.01 glass-distilled water) and $1.0 \mathrm{ml}$ gelatin-thymol blue indicator solution $(600 \mathrm{mg}$ white powder gelatin, $10 \mathrm{mg}$ thymol and $10 \mathrm{mg}$ thymol blue $\mathrm{pH}$ indicator in $100 \mathrm{ml}$ glass-distilled water). Free $\mathrm{Cl}^{-}$were titrated against $\mathrm{Ag}^{+}$generated coulometrically and this resulted in the precipitation of insoluble $\mathrm{AgCl}$. The titration end-point was detected ampherometrically by silver electrodes which measured the appearance of free $\mathrm{Ag}^{+}$and the titration time was directly proportional to the $\mathrm{Cl}^{-}$ concentration. Up to $15.0 \mathrm{ml}$ of samples could be assayed for each $25.0 \mathrm{ml}$ base counting solution and the instrument detected $0 \cdot 2 \mu \mathrm{mol} \mathrm{Cl}^{-}$per sample.

Measurement of dehalogenase activity. Enzyme activity, unless otherwise stated, was measured in crude extracts and, occasionally, in whole organism preparations. Cultures were harvested by centrifuging at $5000 \mathrm{~g}$ for $15 \mathrm{~min}$, and the bacterial pellet was washed once and resuspended in ice-cold $0.02 \mathrm{M}-\mathrm{NaH}_{2} \mathrm{PO}_{4} / \mathrm{Na}_{2} \mathrm{HPO}_{4}$ buffer, $\mathrm{pH} 7 \cdot 0$. In the whole organism assay, bacterial membranes were disrupted by adding $0 \cdot 1 \mathrm{ml}$ toluene to $30 \mathrm{ml}$ bacterial suspension and vigorously mixing for $30 \mathrm{~s}$. For crude extracts, the organisms were disrupted by two passages through a French pressure cell at $83 \mathrm{MPa}$; the remaining whole organisms and cell debris were removed by centrifuging at $30000 \mathrm{~g}$ for $45 \mathrm{~min}$. Dehalogenase activity was assayed in a reaction mixture containing, in $7.5 \mathrm{ml}: 500 \mu \mathrm{mol} \mathrm{NaH} \mathrm{PO}_{4} / \mathrm{Na}_{2} \mathrm{HPO}_{4}$ buffer pH 7.9; $5 \mu \mathrm{mol} \mathrm{NaCl} ; 100$ to $200 \mu \mathrm{mol}$ chlorinated aliphatic acids (solutions adjusted to $\mathrm{pH} \mathrm{7.0)}$ ), to initiate the reaction; and up to $2.0 \mathrm{ml}$ crude extract (or up to $2.0 \mathrm{ml}$ toluene-treated bacterial suspension) containing a maximum of $5.0 \mathrm{mg}$ protein. The incubation temperature was $30^{\circ} \mathrm{C}$ and $1.0 \mathrm{ml}$ samples were removed for $\mathrm{Cl}^{-}$estimation at intervals over the first $45 \mathrm{~min}$ of reaction. Protein was estimated by the Lowry method with bovine serum albumin as the standard. Enzyme specific activities are given as $\mu \mathrm{mol}$ substrate converted (mg protein)-1 $\mathrm{h}^{-1}$. Enzyme activity as a function of assay $\mathrm{pH}$ was determined using the following buffers: $\mathrm{pH} 5 \cdot 7$ to $7 \cdot 9, \mathrm{NaH}_{2} \mathrm{PO}_{4}$ / $\mathrm{Na}_{2} \mathrm{HPO}_{4} ; \mathrm{pH} 7 \cdot 6$ to $8 \cdot 6$, Tris/maleate; $\mathrm{pH} 8 \cdot 6$ to $10 \cdot 0$, glycine/NaOH.

Expression of dehalogenase activity. For the determination of dehalogenase activity in non-growing $P$. putida strain S3, 1.51 succinate-grown, late-exponential phase organisms were harvested at $5000 \mathrm{~g}$ for 15 min and resuspended in $300 \mathrm{ml} 0 \cdot 2 \mathrm{M}-\mathrm{NaH}_{2} \mathrm{PO}_{4} / \mathrm{Na}_{2} \mathrm{HPO}_{4}$ buffer, pH 7.0. Aliquots $(3 \times 100 \mathrm{ml})$ were incubated at $30^{\circ} \mathrm{C}$ with gentle shaking. No additions were made to one of the flasks but to the second and 


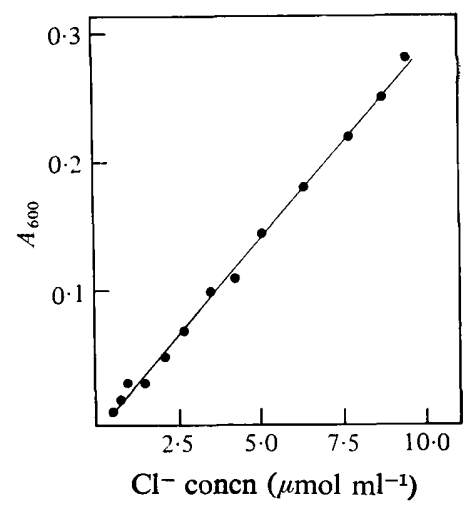

Fig. 1. Differential plot of the increase in culture absorbance against the increase in $\mathrm{Cl}^{-}$concentration for Pseudomonas putida strain P3 grown on 2MCPA in closed culture.

third, 2MCPA and 22DCPA were added, respectively, to give final concentrations' of $0.5 \mathrm{~g} \mathrm{Cl}^{-1}$. After $24 \mathrm{~h}$ incubation under these starvation conditions the organisms were harvested and assayed for dehalogenase activity.

For experiments with growing cultures of $P$. putida strain P3, chlorinated aliphatic acids were added to mid-exponential phase cultures to give final concentrations of $0.5 \mathrm{~g} \mathrm{C}^{-1}$. These cultures were grown in the presence of $0.5 \mu \mathrm{mol} \mathrm{NaCl} \mathrm{ml}{ }^{-1}$ to ensure a low background level of $\mathrm{Cl}^{-}$that facilitated accurate $\mathrm{Cl}^{-}$estimation. In some experiments, the appearance of dehalogenase activity was measured in terms of dehalogenation of the inducer compound only, while in others, organisms were harvested and assayed for dehalogenase activity against a range of substrates.

Thermal stability of dehalogenase activity. Crude extracts were incubated at $50^{\circ} \mathrm{C}$, and samples were taken at intervals over $50 \mathrm{~min}$ incubation, cooled quickly in ice and immediately assayed for MCA, DCA, 2MCPA and 22DCPA dehalogenase activity. The changes in activity with time at $50{ }^{\circ} \mathrm{C}$ were expressed as percentages of the initial activity for each substrate.

Materials. All chemicals were of the highest purity commercially available. MCA was obtained from May \& Baker, Dagenham; DCA and 2MCPA from Koch-Light; TCA from Sigma; 23DCPA and 2MCBA from Fluka (supplied by Fluorochem, Glossop, Dorset); 3MCBA from Pfaltz \& Bauer, Flushing, N.Y., U.S.A.; 3MCPA from Hopkin \& Williams, Chadwell Heath, Essex; and 4MCBA from R. N. Emanuel, Wembley, London. 22DCPA was purified by fractional distillation from technical grade material provided by the Dow Chemical Co., Kings Lynn, Norfolk.

\section{RESULTS}

\section{Growth characteristics of Pseudomonas putida strains S3 and P3}

The two strains of $P$. putida had similar specific growth rates $(\mu)$ when the carbon and energy sources were propionate $\left(\mu=0.30 \mathrm{~h}^{-1}\right)$, lactate $\left(\mu=0.41 \mathrm{~h}^{-1}\right)$, pyruvate $(\mu=$ $\left.0.41 \mathrm{~h}^{-1}\right)$ and succinate $\left(\mu=0.44 \mathrm{~h}^{-1}\right)$. They differed in their capacity to grow on chlorinated propionates: $P$. putida strain P3 grew on 2MCPA $\left(\mu=0.30 \mathrm{~h}^{-1}\right)$ and 22DCPA $(\mu=$ $0.12 \mathrm{~h}^{-1}$ ), whereas $P$. putida strain S3 was unable to grow on 2MCPA or 22DCPA in liquid culture. Pseudomonas putida strain S3, however, did produce very small colonies after 48 to $72 \mathrm{~h}$ on solidified medium when 2MCPA was the carbon source. The growth of $P$. putida strain P3 on 2MCPA and 22DCPA was directly correlated with the dechlorination of the carbon sources since differential plots of culture absorbance against $\mathrm{Cl}^{-}$release were linear (Fig. 1).

Pseudomonas putida strain P3 did not show diauxic growth in medium containing any combination of unchlorinated carbon source with 2MCPA or 22DCPA, both substrates being used simultaneously. The addition of either 2MCPA or 22DCPA to exponentially growing cultures of $\boldsymbol{P}$. putida strain $\mathbf{P} 3$ caused only minor perturbations in growth (Fig. $2 a$ ) and resulted in the appearance of $\mathrm{Cl}^{-}$, indicative of the metabolism of the chlorinated aliphatic acids, after a lag period varying between 60 and $90 \mathrm{~min}$ (Fig. $2 b$ ). The simultaneous 

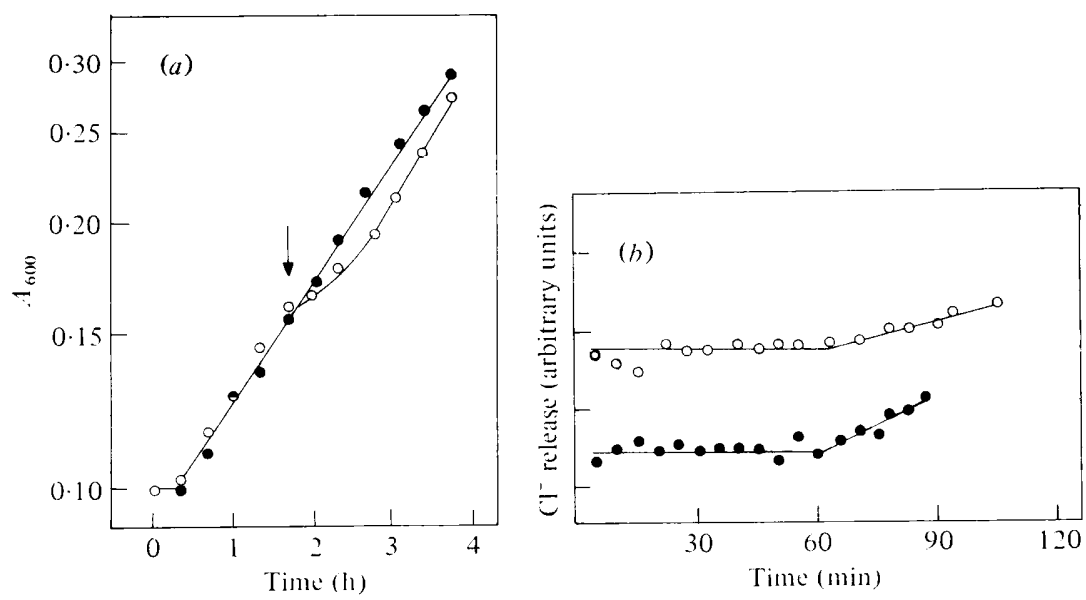

Fig. 2. Effect of addition of 2MCPA and 22DCPA to cultures of Pseudomonas putida strain P3 growing on succinate. (a) Effect on growth; arrow indicates time of addition of either 2MCPA (O) or 22DCPA (O) to give final concentrations of $0.5 \mathrm{~g} \mathrm{Cl}^{-1}$. (b) Release of $\mathrm{Cl}^{-}$from 2MCPA (O) and 22DCPA (O) added at time 0 (arrowed in $a$ ).
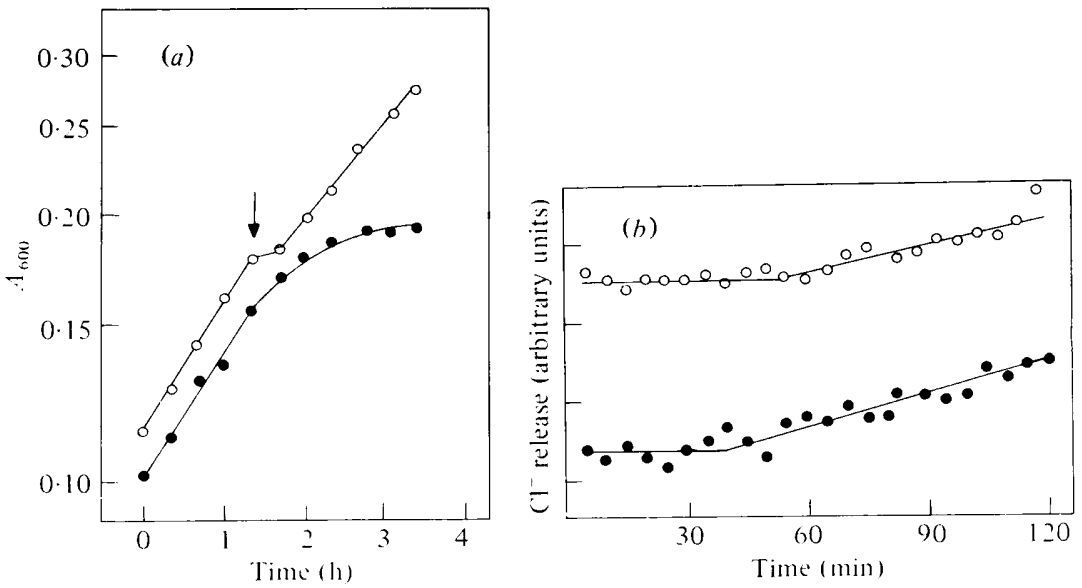

Fig. 3. Effect of addition of MCA and DCA to cultures of Pseudomonas putida strain P3 growing on succinate. (a) Effect on growth; arrow indicates time of addition of either MCA $(\bigcirc)$ or DCA (O) to give final concentrations of $0.5 \mathrm{~g} \mathrm{Cl}^{-1}$. (b) Release of $\mathrm{Cl}^{-}$from MCA $(O)$ and DCA added at time 0 (arrowed in $a$ ).

addition of chloramphenicol (final concentration $2 \cdot 0 \mu \mathrm{g} \mathrm{ml}^{-1}$ ) completely prevented $\mathrm{Cl}^{-}$ release. The addition of 2MCPA or 22DCPA to exponentially growing cultures of $P$. putida strain $\mathrm{S} 3$ did not influence the growth nor did it induce any significant $\mathrm{Cl}^{-}$release.

Pseudomonas putida strain P3 could not utilize either MCA or DCA as the sole carbon source although addition of these substrates to cultures growing exponentially on succinate resulted in their dehalogenation, $\mathrm{Cl}^{-}$release occurring after lag periods varying between 40 and 60 min (Fig. $3 b$ ). The addition of both MCA and DCA affected growth: DCA caused growth to cease 90 min after its addition but growth resumed once dehalogenation was complete (Fig. $3 a$ ). In contrast $P$. putida strain S3 was unable to dechlorinate added MCA or DCA.

Neither strain was able to use TCA, 3MCPA, 23DCPA, 2MCBA or 3MCBA as carbon and energy sources for growth. 
Table 1. Dehalogenase activity against a range of chlorinated aliphatic acids in Pseudomonas putida strain $\mathrm{P} 3$ grown on $2 M C P A$ and in $P$. putida strain S3 starved for $24 h$ in the presence of $2 M C P A$

Enzyme activities were calculated on the basis of $\mu \mathrm{mol}$ substrate converted (mg protein) ${ }^{-1} \mathrm{~h}^{-1}$ and relative activities are expressed as a percentage of the activity against 2MCPA.

\begin{tabular}{|c|c|c|c|}
\hline \multirow[b]{3}{*}{$\begin{array}{l}\text { Dehalogenase } \\
\text { substrate }\end{array}$} & \multicolumn{3}{|c|}{ Relative enzyme activity } \\
\hline & \multicolumn{2}{|c|}{ Strain P3 } & \multirow{2}{*}{$\begin{array}{c}\text { Strain S3 } \\
\text { Fresh whole } \\
\text { organisms }\end{array}$} \\
\hline & $\begin{array}{l}\text { Fresh crude } \\
\text { extract }\end{array}$ & $\begin{array}{l}\text { Crude extract } \\
\text { stored for } 24 \mathrm{~h} \\
\text { at } 4^{\circ} \mathrm{C}\end{array}$ & \\
\hline MCA & 168 & 123 & ND \\
\hline DCA & 90 & 66 & 244 \\
\hline TCA & 13 & 16 & ND \\
\hline 2MCPA & 100 & 100 & 100 \\
\hline 3MCPA & 3 & 8 & ND \\
\hline 22DCPA & 48 & 43 & 58 \\
\hline 23DCPA & 18 & ND & ND \\
\hline $2 \mathrm{MCBA}$ & 17 & 50 & ND \\
\hline $3 \mathrm{MCBA}$ & 0 & 0 & ND \\
\hline 4MCBA & 0 & 0 & ND \\
\hline
\end{tabular}

ND, Not determined.

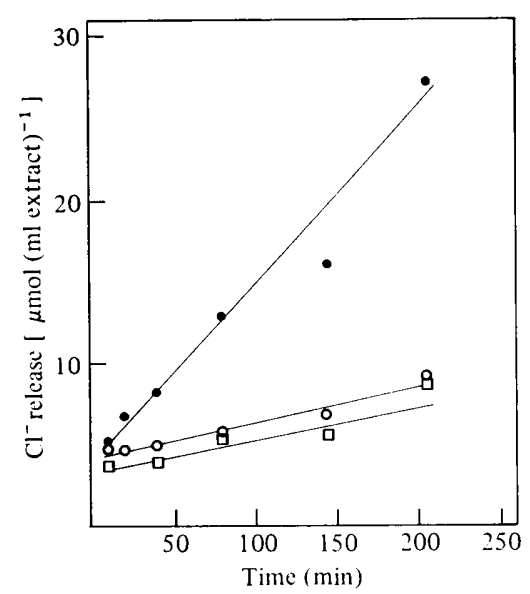

Fig. 4. Dehalogenase activity in Pseudomonas putida strain S3 originally grown on succinate and subsequently starved for $24 \mathrm{~h}$ in the presence of 2MCPA. Activity was measured against DCA $(\bullet), 2 \mathrm{MCPA}(O)$ and 22DCPA $(\square)$.

\section{Dehalogenase activity in Pseudomonas putida strains S3 and $\mathrm{P} 3$}

Enzyme activity and specificity. Extracts of $P$. putida strain P3 grown on 2MCPA or 22DCPA contained dehalogenase activity whereas no activity could be detected in organisms grown on succinate, pyruvate, lactate or propionate. Table 1 shows that the major activities were for MCA, DCA, 2MCPA and 22DCPA. In addition, there was significant dehalogenation activity against a number of other substrates substituted on the $\mathrm{C}-2$ position, particularly $2 \mathrm{MCBA}$, and extremely low activity against one C-3 substituted compound, 3MCPA. There was considerable variation in the ratios of the relative enzyme activities in different crude preparations; the one exception was the 2MCPA:22DCPA ratio which 
Table 2. Apparent Michaelis-Menten $\left(K_{\mathrm{m}}\right)$ constants for dehalogenase activity in crude extracts of Pseudomonas putida strain P3 grown on $2 M C P A$ in closed culture

\begin{tabular}{ccccc} 
Expt & \multicolumn{4}{c}{ Apparent } \\
1 & MCA & DCA & 2MCPA & 22DCPA \\
2 & 8.0 & 0.99 & 2.9 & 1.2 \\
2 & ND & 0.95 & 3.1 & 2.6
\end{tabular}

ND, Not determined.

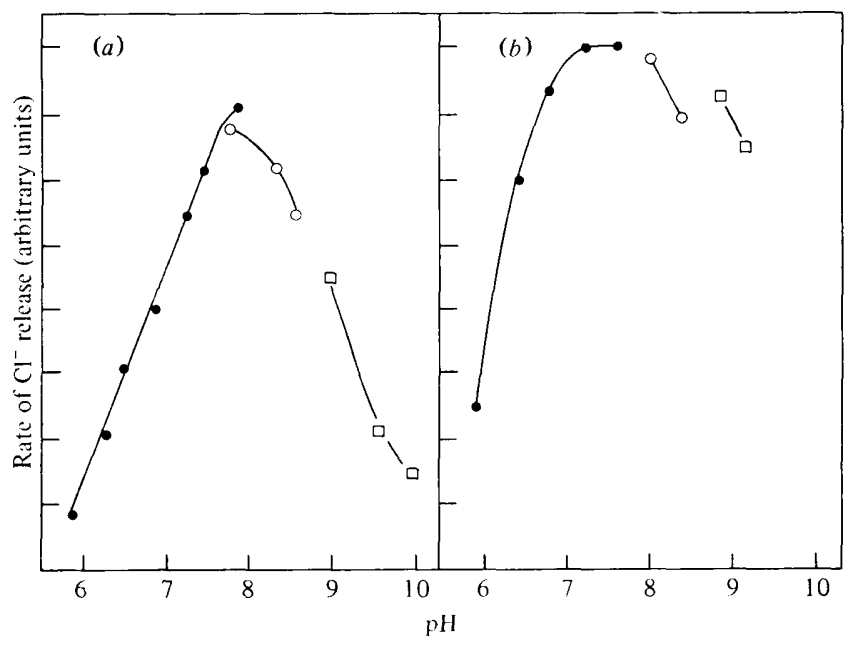

Fig. 5. Effect of pH on dehalogenase activity against DCA $(a)$ and 2MCPA $(b)$. Buffers used were $\mathrm{NaH}_{2} \mathrm{PO}_{4} / \mathrm{Na}_{2} \mathrm{HPO}_{4}(\bullet)$, Tris/maleate $(\bigcirc)$ and glycine/NaOH $(\square)$.

remained constant at $2: 1$. Furthermore, marked changes in the various dehalogenase activities occurred in extracts stored at $4{ }^{\circ} \mathrm{C}$ for varying periods of time, there being a particularly rapid loss of DCA dehalogenation capability (Table 1). These variations in the enzyme specific activities are discussed further in relation to chemostat experiments.

Dehalogenase activity in $P$. putida strain S3 was more difficult to demonstrate because this organism could not be grown on chlorinated propionates or acetates. However, specific enzyme activities against DCA, 2MCPA and 22DCPA, at least an order of magnitude lower than those recorded in strain P3, were detected in organisms first grown on succinate and subsequently starved for $24 \mathrm{~h}$ in the presence of 2MCPA (Table 1, Fig. 4). No dehalogenase activity was detected in bacterial suspensions starved in the absence of a chlorinated compound or in the presence of 22DCPA. Activity could not be detected against the other potential substrates.

Apparent Michaelis-Menten constants for the four major substrates were determined for crude extracts of 2MCPA-grown $P$. putida strain P3 from Lineweaver-Burk plots (Table 2). There was insufficient activity to determine the apparent $K_{\mathrm{m}}$ values for the dehalogenase activity in $P$. putida strain S3.

pH optima. The dehalogenation activity for the four major substrates had two markedly different $\mathrm{pH}$ profiles. The $\mathrm{pH}$ optima for MCA and DCA dehalogenation lay between $\mathrm{pH}$ $7 \cdot 9$ and $8 \cdot 1$ and the activity declined rapidly on either side of this optimum (Fig. $5 a$ ). The $\mathrm{pH}$-activity profiles for 2MCPA and 22DCPA, however, had considerably broader optima with a mid-point at approximately $\mathrm{pH} 8 \cdot 0$ (Fig. $5 b$ ).

Dehalogenase activity in chemostat cultures. In view of the considerable variations in enzyme specific activity in closed cultures, the influence of growth conditions and growth 


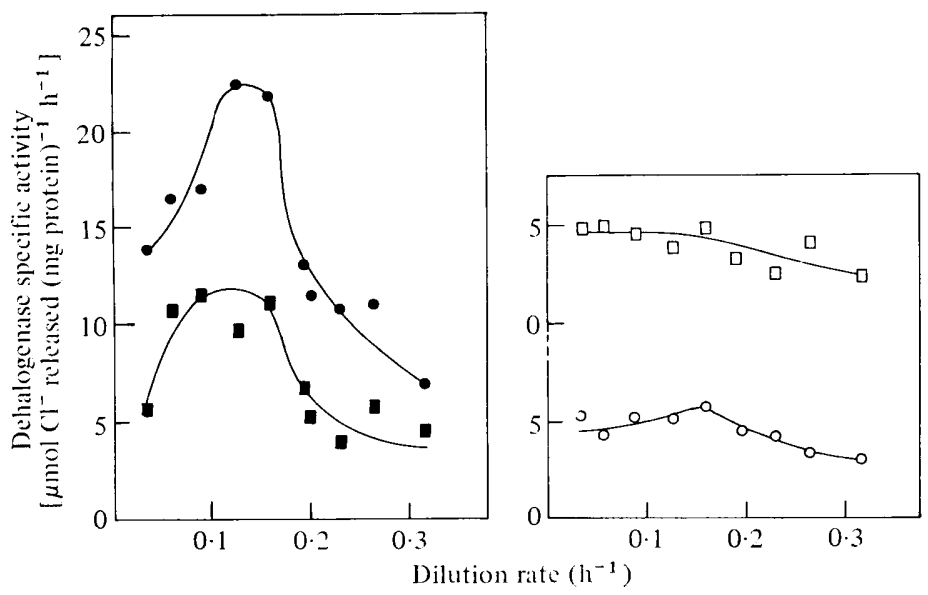

Fig. 6. Influence of dilution rate on the dehalogenase specific activity of Pseudomonas putida strain P3 grown under 2MCPA-limited conditions. Dehalogenase activity was measured against DCA (O), MCA (घ), 2MCPA (O) and 22DCPA ( $\square$ ).

Table 3. Dehalogenase activity against a range of chlorinated aliphatic acids in Pseudomonas putida strains $\mathrm{P} 3$ and S3 grown in chemostat culture

Dehalogenase specific activities are expressed as $\mu$ mol substrate converted (mg protein) ${ }^{-1} \mathrm{~h}^{-1}$. Relative enzyme activities are expressed as a percentage of the activity against 2MCPA. The dehalogenase activities for $P$. putida strain S3 were all measured at $D=0 \cdot 10 \mathrm{~h}^{-1}$; no attempt was made to determine $D$ for maximum activity.

\begin{tabular}{|c|c|c|c|c|c|c|}
\hline \multirow[b]{2}{*}{ Strain } & \multicolumn{3}{|c|}{ Growth conditions } & \multicolumn{3}{|c|}{ Dehalogenase } \\
\hline & $\begin{array}{l}\text { Growth- } \\
\text { limiting } \\
\text { substrate }\end{array}$ & $\begin{array}{l}\text { Enzyme } \\
\text { inducer }\end{array}$ & $\begin{array}{c}D \text { for } \\
\text { maximum } \\
\text { activity }\left(h^{-1}\right)\end{array}$ & Substrate & $\begin{array}{l}\text { Maximum } \\
\text { specific } \\
\text { activity }\end{array}$ & $\begin{array}{c}\text { Relative } \\
\text { enzyme } \\
\text { activity }\end{array}$ \\
\hline P3 & 2MCPA & 2MCPA & $\begin{array}{l}0 \cdot 13 \\
0 \cdot 13 \\
0 \cdot 04-0 \cdot 15 \\
0 \cdot 04-0 \cdot 15\end{array}$ & $\begin{array}{l}\text { MCA } \\
\text { DCA } \\
\text { 2MCPA } \\
\text { 22DCPA }\end{array}$ & $\begin{array}{r}12 \cdot 0 \\
11 \cdot 2 \\
5 \cdot 3 \\
2 \cdot 5\end{array}$ & $\begin{array}{r}226 \\
211 \\
100 \\
47\end{array}$ \\
\hline P3 & Succinate & DCA & $\begin{array}{l}0 \cdot 10 \\
0 \cdot 08 \\
0 \cdot 10 \\
0 \cdot 10\end{array}$ & $\begin{array}{l}\text { MCA } \\
\text { DCA } \\
\text { 2MCPA } \\
\text { 22DCPA }\end{array}$ & $\begin{array}{r}29 \cdot 3 \\
38 \cdot 5 \\
17 \cdot 0 \\
7 \cdot 9\end{array}$ & $\begin{array}{r}172 \\
226 \\
100 \\
46\end{array}$ \\
\hline S3 & Succinate & 2MCPA & $\begin{array}{l}\text { ND } \\
\text { ND } \\
\text { ND } \\
\text { ND }\end{array}$ & $\begin{array}{l}\text { MCA } \\
\text { DCA } \\
\text { 2MCPA } \\
\text { 22DCPA }\end{array}$ & $\begin{array}{l}0.9 \\
0.6 \\
0.8 \\
0.3\end{array}$ & $\begin{array}{r}113 \\
75 \\
100 \\
38\end{array}$ \\
\hline
\end{tabular}

ND, Not determined.

rate on dehalogenase activity was examined for both strains in chemostat culture. Two different patterns of dehalogenase specific activity as a function of dilution rate were observed in steady-state cultures of $P$. putida strain P3 growing on 2MCPA as the limiting substrate (Fig. 6). The 2MCPA and 22DCPA dehalogenase specific activity changes were similar, each showing a slight increase with decreasing dilution rate and an indication of a small peak of activity at a dilution rate of approximately $D=0.15 \mathrm{~h}^{-1}$. With MCA and DCA as the substrates, however, a pattern of changing enzyme specific activity characteristic of catabolic enzymes (Clarke \& Lilly, 1969; Dean, 1972) was observed. There were significant activity maxima at $D=0.13 \mathrm{~h}^{-1}$ : with increasing dilution rate activity declined, 


\section{Table 4. Induction of dehalogenase activity in Pseudomonas putida strain $\mathrm{P} 3$ by a range of chlorinated aliphatic acids}

Dehalogenase specific activities are expressed as $\mu$ mol substrate converted (mg protein) ${ }^{-1} \mathrm{~h}^{-1}$. Values in parentheses indicate the activities as a percentage of those against 2MCPA.

Dehalogenase activity

\begin{tabular}{|c|c|c|c|c|}
\hline Inducer & MCA & DCA & 2MCPA & 22DCPA \\
\hline MCA & $11 \cdot 9(290)$ & $9 \cdot 0(220)$ & $4 \cdot 1(100)$ & $1.9(46)$ \\
\hline DCA & $5 \cdot 8(290)$ & $2 \cdot 2(110)$ & $2 \cdot 0(100)$ & $1 \cdot 1(55)$ \\
\hline TCA & $14.9(257)$ & $18 \cdot 8(324)$ & $5 \cdot 8(100)$ & $3 \cdot 4(58)$ \\
\hline 2МCPA & $15 \cdot 4(223)$ & $21 \cdot 2(307)$ & $6.9(100)$ & $3 \cdot 7(54)$ \\
\hline 3MCPA & $6 \cdot 7(372)$ & $12 \cdot 2(678)$ & $1.8(100)$ & $1 \cdot 3(72)$ \\
\hline 22DCPA & $19 \cdot 9(243)$ & $21 \cdot 7(265)$ & $8 \cdot 2(100)$ & $5 \cdot 4(65)$ \\
\hline 2MCBA & $15 \cdot 5(267)$ & $15 \cdot 3(264)$ & $5 \cdot 8(100)$ & $3 \cdot 4(59)$ \\
\hline 3MCBA & $5 \cdot 2(273)$ & $5 \cdot 0(263)$ & $1.9(100)$ & $1 \cdot 4(74)$ \\
\hline 4MCBA & $3 \cdot 0(300)$ & $5 \cdot 7(570)$ & $1 \cdot 0(100)$ & $0.7(70)$ \\
\hline
\end{tabular}

presumably as a result of catabolite repression, while activity also declined with decreasing dilution rate due to the gradual lowering of the residual growth-limiting substrate/inducer concentration. These patterns of changes in enzyme activity with dilution rate are consistent with the considerable variations in the relative enzyme activities observed in closed culture. The maximum enzyme activities observed in chemostat culture (Table 3 ) showed a constant ratio of activities for 2MCPA :22DCPA, which was also similar to the ratios found in closed culture (Table 1). However, the MCA:2MCPA and DCA:2MCPA activity ratios were variable and significantly different from the average ratios shown in closed culture, particularly the latter ratio which indicated a threefold increase in the DCA activity.

Pseudomonas putida strain P3 was also grown on succinate in the presence of DCA by first establishing a steady-state chemostat culture growing on succinate alone and subsequently switching the medium supply to the mixed substrates. As a result of the initial gradual addition of DCA to the growing culture, adequate dehalogenation activity was induced to ensure the complete degradation of the supplied DCA and thereby prevent the accumulation of growth inhibitory concentrations of undegraded DCA. In these cultures, the MCA and DCA dehalogenase activity profiles, as a function of dilution rate, were similar to those of 2MCPA-limited cultures, although the peaks of activity occurred at lower dilution rates (Table 3). Furthermore, in the chemostat cultures grown on succinate with DCA, the maximum enzyme specific activities were considerably higher, the DCA dehalogenase activity being $3 \cdot 5$ times greater than in 2MCPA-limited chemostat cultures. Similarly, 2MCPA and 22DCPA dehalogenase activities were approximately three times higher in the presence of DCA and showed obvious peaks of activity at a common dilution rate of $D=0 \cdot 10 \mathrm{~h}^{-1}$. With the exception of the MCA dehalogenase activity, the relative enzyme activities were similar in DCA- and 2MCPA-induced cultures and there was a constant 2MCPA:22DCPA ratio of about 2:1 in all steady-state cultures examined.

Organisms of $P$. putida strain S3 synthesized low levels of dehalogenase activity against the four major substrates when exposed to 2MCPA in chemostat cultures growing on succinate at a single dilution rate of $0 \cdot 10 \mathrm{~h}^{-1}$ (Table 3). The specific activities reported are the average of five separate determinations; no attempt was made to measure the enzyme activities as a function of growth rate. These results are consistent with the inducibility of dehalogenase in non-growing organisms of strain S3 by 2MCPA reported above.

Induction of dehalogenase activity by chlorinated aliphatic acids. The capacity of metabolizable and non-metabolizable chlorinated aliphatic acids to induce dehalogenase activity against MCA, DCA, 2MCPA and 22DCPA in $P$. putida strain P3 was examined in closed cultures growing on succinate (Table 4). All the compounds examined were able to induce dehalogenase activity against all four enzyme substrates, although some, including MCA, 


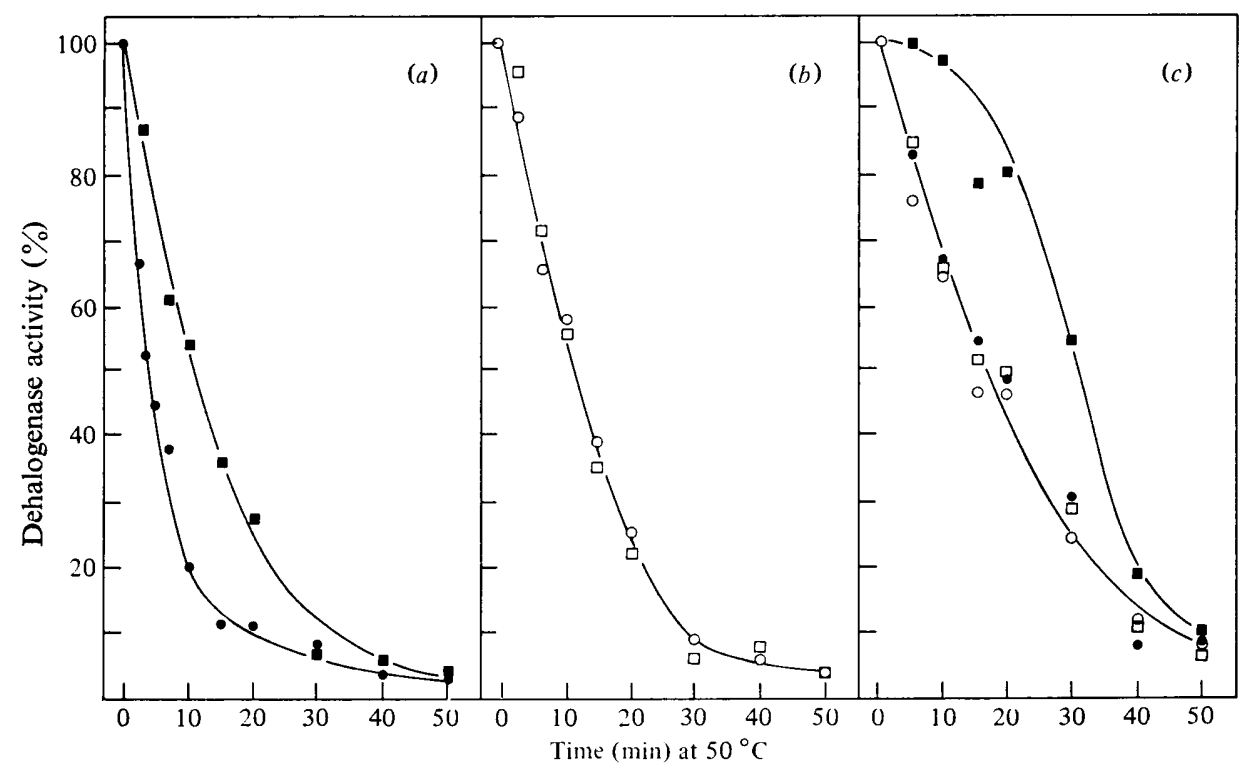

Fig. 7. Stability of dehalogenase activities during incubation at $50^{\circ} \mathrm{C}$ of freshly prepared crude extracts $(a, b)$ and crude extracts stored at $4{ }^{\circ} \mathrm{C}$ for $48 \mathrm{~h}(c)$ of Pseudomonas putida strain P3 grown on 2MCPA in closed culture. The activities against DCA (O), MCA ( $), 2 \mathrm{MCPA}(\mathrm{O})$ and 22DCPA $(\square)$ are expressed as a percentage of the maximum activity for each substrate at time 0 .

Table 5. Relative dehalogenase activities in freshly prepared extracts of Pseudomonas putida strain $\mathrm{P} 3$ after incubation at $50^{\circ} \mathrm{C}$ for various times

The DCA dehalogenase activity was standardized to $1 \cdot 0$ at each incubation time and all other activities are expressed relative to this.

Incubation time at $50{ }^{\circ} \mathrm{C}(\mathrm{min})$

0
3
7
10
15
20
30

\begin{tabular}{cccc}
\multicolumn{4}{c}{ Relative dehalogenase activity } \\
\hline MCA & DCA & 2MCPA & 22DCPA \\
1.0 & 1.0 & 0.8 & 0.4 \\
1.7 & 1.0 & 1.4 & $0 \cdot 7$ \\
1.5 & 1.0 & 1.2 & $0 \cdot 7$ \\
3.4 & 1.0 & 2.8 & $1 \cdot 3$ \\
6.7 & 1.0 & 5.6 & $2 \cdot 4$ \\
7.6 & 1.0 & 5.4 & $2 \cdot 3$ \\
4.6 & 1.0 & $2 \cdot 4$ & 1.8
\end{tabular}

TCA, 2MCPA, 22DCPA and 2MCBA, were better inducers than others. There were considerable variations in the absolute enzyme specific activities and variations in the ratios of activities against MCA:DCA:2MCPA; for example, the DCA:2MCPA activity ratio varied from $1 \cdot 1: 1 \cdot 0$ to $6 \cdot 8: 1 \cdot 0$. However, with the exception of the induction by 3 MCPA, $3 \mathrm{MCBA}$ and 4MCBA, the ratios of activities against 2MCPA:22DCPA were constant and in line with the growth experiments.

Thermal stability of dehalogenase activity. The variation in dehalogenase activities in the growth and induction experiments suggested that $P$. putida strain P3 contained more than one dehalogenase protein and that each catalysed dechlorination of one or more different substrates. Further evidence for this possibility was obtained from thermal denaturation experiments. The denaturation curves for freshly prepared extracts of $P$. putida strain P3 showed marked differences depending on the substrate (Fig. $7 a, b$ ). Thus, over $80 \%$ of 
Table 6. Relative dehalogenase activities in extracts of Pseudomonas putida strain P3 stored at $4{ }^{\circ} \mathrm{C}$ for $48 \mathrm{~h}$ and subsequently incubated at $50{ }^{\circ} \mathrm{C}$ for various times

The DCA dehalogenase activity was standardized to 1.0 at each incubation time and all other activities are expressed relative to this.

Incubation
time at $50^{\circ} \mathrm{C}$
(min)
0
5
10
15
20
30

\begin{tabular}{cccc}
\multicolumn{4}{c}{ Relative dehalogenase activity } \\
\hline MCA & DCA & 2MCPA & 22DCPA \\
1.6 & $1 \cdot 0$ & $2 \cdot 1$ & 1.6 \\
2.1 & 1.0 & $2 \cdot 1$ & 1.5 \\
2.6 & $1 \cdot 0$ & $2 \cdot 1$ & 1.6 \\
2.6 & 1.0 & $2 \cdot 0$ & 1.4 \\
3.0 & $1 \cdot 0$ & $2 \cdot 1$ & 1.6 \\
3.3 & $1 \cdot 0$ & $2 \cdot 0$ & 1.3
\end{tabular}

the original DCA dehalogenase activity was lost after $10 \mathrm{~min}$ incubation at $50{ }^{\circ} \mathrm{C}$ whereas the MCA, 2MCPA and 22DCPA dehalogenase activities were reduced by only $40 \%$ during the same period. A comparison of the activity ratios showed that the loss of DCA dehalogenase activity was not correlated with the loss of MCA, 2MCPA and 22DCPA dehalogenase activity (Table 5). There was a parallel loss of 2MCPA and 22DCPA dehalogenase activities which also seemed to be related to the loss of MCA activity. We had observed previously (see above) that much of the DCA dehalogenase activity in crude extracts was lost after storage at $4{ }^{\circ} \mathrm{C}$. A comparison of the thermal denaturation curves for stored extracts showed a strikingly parallel loss of activity for DCA, 2MCPA and 22DCPA (Fig. 7c, Table 6). In these extracts the MCA dehalogenase activity increased relative to standard DCA, 2MCPA or 22DCPA activities with an increasing period of denaturation. These results suggested that perhaps the MCA dehalogenase activity was not correlated with the other three activities.

\section{DISCUSSION}

Pseudomonas putida strain P3 was isolated from a stable mixed culture growing on 22DCPA and which initially contained P. putida S3 (Senior et al., 1976). It was suggested that strain P3 was a mutant of strain S3 differing in its capacity to metabolize chlorinated aliphatic acids and its dehalogenase activity. Mono-culture chemostat experiments (Senior et al., 1976) and conventional selection experiments with and without mutagenesis on solid medium (A. J. Weightman \& J. H. Slater, unpublished) have shown that it is possible to select for other strains from S3 that are phenotypically similar to P3. The results reported here show that the capacity of strain P3 to grow on chlorinated propionic acid was due to considerably elevated dehalogenase activities compared with strain S3, i.e. activities that were able to sustain the observed growth rates. The starvation experiments suggested that strain S3 was unable to use 22DCPA as a carbon source because the substrate did not induce dehalogenase activity, whereas the low enzyme activities induced by 2MCPA may have been high enough to account for its slow growth on this substrate. The inability of $P$. putida strain P3 to utilize MCA or DCA as carbon and energy sources, despite high dehalogenase activities towards these compounds, remains obscure and is currently being examined.

The capacity of the mutant $P$. putida strain P3 to grow on chlorinated aliphatic acids was the result of a general increase in a number of dehalogenase activities rather than a specific alteration towards a 22DCPA-specific dehalogenase and possibly reflected an alteration in the organism's regulatory mechanism. Strain P3 was not a constitutive mutant as may have been expected as a result of selection in continuous-flow culture (Hartley et al., 1972). The dehalogenase activities were induced despite the presence of alternative, readily metabolizable carbon sources, a property that may be significant since the strain was selected 
in an environment that contained other carbon sources. Moreover, all the dehalogenase activities were induced by a range of metabolizable and non-metabolizable chlorinated aliphatic acids, some of which were not involved in the original selection of strain P3.

Dehalogenase activity was mainly against C-2 substituted aliphatic acids, an observation in accord with the known properties of other dehalogenases (Davies \& Evans, 1962; Kearney et al., 1964; Little \& Williams, 1971; Goldman, 1972). Compared with other pseudomonads, $P$. putida strain P3 showed significant differences in the range of substrates hydrolysed and the relative enzyme activities. For example, extracts of Pseudomonas dehalogens NCIB 9062 (strain K of Jensen, 1960) showed activity mainly towards MCA and to DCA at $17 \%$ of the MCA rate. There was no activity in crude extracts of organisms grown on MCA against TCA, 2MCPA, 22DCPA or 3MCPA (Davies \& Evans, 1962). Thus, the relative DCA rate was considerably lower than the DCA rate in $P$. putida strain P3 and differed significantly in its response to chlorinated propionates. Pseudomonas dehalogens NCIB 9061 (strain R of Jensen, 1960) showed activity towards MCA and DCA, as well as 2MCPA and 22DCPA, at 35 and $9 \%$, respectively, of the MCA rate (Little \& Williams, 1971). Here too, in relation to the MCA rate, the activities towards chlorinated propionic acids were lower than in P. putida strain P3 and, furthermore, the 2MCPA :22DCPA activity ratio was greater than in $P$. putida strain P3. The apparent $K_{\mathrm{m}}$ values for the four major substrates in $P$. dehalogens NCIB 9061 were at least an order of magnitude lower than those for same substrates in $P$. putida strain P3. These comparisons strongly suggest that there were major differences in the types of dehalogenases found in different pseudomonads.

The evidence presented in this paper also suggests that $P$. putida strain P3 contained at least two different dehalogenase proteins, one mainly involved in the dehalogenation of chlorinated acetic acids and the other mainly active against the chlorinated propionic acids. Firstly, two characteristically different $\mathrm{pH}$ profiles for each pair of substrates, together with the different dilution rate profiles in chemostat culture, provided some support for this suggestion. Secondly, the marked variations in the relative enzyme activities, particularly between the two groups of substrates, could have been due to variations in the relative proportions of two proteins, depending on growth conditions. The remarkably consistent 2:1 ratio for the 2MCPA:22DCPA activities in organisms grown in both closed and open culture indicated that these activities were common to a single dehalogenase. Thirdly, the thermal denaturation experiments with freshly prepared crude extracts showed a significantly different pattern for the loss of DCA activity which was more rapid than the loss of the 2MCPA and 22DCPA activities. These results indicated that the DCA activity was associated with a different protein from the 2MCPA and 22DCPA activities and, moreover, the parallel loss of activity against chlorinated propionates further indicated an association of these two activities. In addition, much of the DCA and MCA activity was cold labile and lost upon storage at $4{ }^{\circ} \mathrm{C}$ for $48 \mathrm{~h}$. In these stored extracts the residual DCA activity seemed to be associated with the 2MCPA and 22DCPA dehalogenase activity. The loss of MCA activity was ambiguous, principally because its thermal denaturation curve followed that for 2MCPA and 22DCPA activity loss in freshly prepared extracts. Although MCA activity was lost at $4{ }^{\circ} \mathrm{C}$, the MCA denaturation curve in stored crude extracts was strikingly different. We have recently purified the dehalogenases from $P$. putida strain P3 (Weightman et al., 1979) and shown that there are two enzymes. One has activity towards 2MCPA and 22DCPA principally but with significant MCA activity and slight DCA activity. The second has major activity against DCA, significant activity against MCA but no activity towards 2MCPA and 22DCPA. These observations are entirely consistent with the results reported here and may serve to explain the somewhat anomalous behaviour for the MCA dehalogenase activity because it is associated with both proteins. There has been one previous demonstration that an organism contained two different dehalogenases (Goldman et al., 1968) but each was separately induced, one by DCA and the other by MCA. 
We thank The Royal Society for a Scientific Investigations Grant to J.H.S.; the Science Research Council for Research Studentships for D.L. and E.S. and Mrs D. E. Sanders for excellent technical assistance.

\section{REFERENCES}

Audus, L. J. (1976). Herbicides: Physiology, Biochemistry, Ecology. London: Academic Press.

Berry, E. K. M., Skinner, A. J. \& CoOper, R. A. (1976). The bacterial degradation of 'Dalapon'. Proceedings of the Society for General Microbiology 4, 38-39.

Burge, W. D. (1969). Populations of Dalapondegrading bacteria in soil as influenced by additions of Dalapon and other carbon sources. Applied Microbiology 17, 545-550.

Clarke, P. H. \& Lilly, M. D. (1969). The regulation of enzyme synthesis during growth. Symposia of the Society for General Microbiology 19, 113-159.

Davies, J. I. \& Evans, W. C. (1962). The elimination of halide ions from aliphatic halogen-substituted organic acids by an enzyme preparation from Pseudomonas dehalogens. Biochemical Journal 82, 50P-51P.

DEAN, A. C. R. (1972). Influence of environment on the control of enzyme synthesis. Journal of Applied Chemistry and Biotechnology 22, 245-259.

FowDEN, L. (1968). The occurrence and metabolism of carbon-halogen compounds. Proceedings of the Royal Society B171, 5-18.

Foy, C. L. (1969). The chlorinated aliphatic acids. In Degradation of Herbicides. Edited by P. C. Kearney \& D. D. Kaufman, pp. 207-253. New York: Marcel Dekker.

Goldman, P. (1965). The enzymatic cleavage of the carbon-fluorine bond in fluoroacetate. Journal of Biological Chemistry 240, 3434-3438.

Goldman, P. (1972). Enzymology of carbonhalogen bonds. In The Degradation of Synthetic Organic Molecules in the Biosphere, pp. 147165. Washington: National Academy of Sciences, U.S.A.

Goldman, P., Milne, G. W. A. \& Keister, D. B. (1968). Carbon-halogen bond cleavage. III. Studies on bacterial halidohydrolases. Journal of Biological Chemistry 243, 428-434.

Hartley, B. S., Burleigh, B. D., Midwinter, G. G., Moore, C. H., Morris, H. R., Rigby, P. W. J., SMITH, M. J. \& TAYLOR, S. S. (1972). In Enzymes: Structure and Function, pp. 151-176. Edited by J. Drenth, R. A. Oosterbaan \& C. Velgar. Amsterdam: North-Holland.

Hirsch, P. \& AleXander, M. (1960). Microbial decomposition of halogenated propionic and acetic acids. Canadian Journal of Microbiology 6, 241-249.

JENSEN, H. L. (1957a). Decomposition of chloroorganic acids by fungi. Nature, London 180, 1416.

JENSEN, H. L. (1957b). Decomposition of chloro- substituted aliphatic acids by soil bacteria. Canadian Journal of Microbiology 3, 151-164.

JENSEN, H. L. (1959). Decomposition of chlorinesubstituted organic acids by fungi. Acta agriculturae scandinavica $9,421-434$.

Jensen, H. L. (1960). Decomposition of chloroacetates and chloropropionates by bacteria. Acta agriculturae scandinavica 10, 83-103.

JENSEN, H. L. (1963). Carbon nutrition of some microorganisms decomposing halogen-substituted aliphatic acids. Acta agriculturae scandinavica 13, 404-412.

Kearney, P. C. \& Kaufman, D. D. (editors) (1969). Degradation of Herbicides. New York: Marcel Dekker.

Kearney, P. C., Kaufman, D. D. \& Beall, M. L. (1964). Enzymatic dehalogenation of 2,2'-dichloropropionate. Biochemical and Biophysical Research Communications 14, 29-33.

LEASURE, J. K. (1964). The halogenated aliphatic acids. Journal of Agricultural and Food Chemistry $12,40-43$.

Little, M. \& Williams, P. A. (1969). The purification and some properties of a monohaloacetate dehalogenase from Pseudomonas dehalogens NCIB 9061. Biochemical Journal 114, 11P-12P.

Little, M. \& Williams, P. A. (1971). A bacterial halidohydrolase. Its purification, some properties and its modification by specific amino acid reagents. European Journal of Biochemistry 21, 99-109.

MACGREGoR, A. N. (1963). The decomposition of dichloropropionate by soil bacteria. Journal of General Microbiology 30, 497-501.

Magee, L. A. \& Colmer, A. R. (1959). Decomposition of 2,2-dichloropropionic acid by soil bacteria. Canadian Journal of Microbiology $\mathbf{5}$, 255-260.

Senior, E., Bull, A. T. \& Slater, J. H. (1976). Enzyme evolution in a microbial community growing on the herbicide Dalapon. Nature, London 262, 476-479.

Slater, J. H., Weightman, A. J., Senior, E. \& Bull, A. T. (1976). The dehalogenase from Pseudomonas putida. Proceedings of the Society for General Microbiology 4, 39-40.

SuIDA, J. F. \& DEBERNARDIS, J. F. (1973). Naturally occurring halogenated organic compounds. Lloydia 36, 107-143.

Weightman, A. J, Slater, J. H. \& Bull, A. T. (1979). Cleavage of the carbon-chlorine bond by Pseudomonas putida. Society for General Microbiology Quarterly 6, 76-77. 